\title{
Association between serum albumin and cardiovascular diseases among adult population of Kaski district, Nepal
}

\author{
Yadav Naval Kishor ${ }^{1,2}$, Pokharel Daya Ram ${ }^{1}$, Kathayat Goma $^{1}$, Sigdel Manoj ${ }^{1}$, Hussian Imran ${ }^{2}$
}

\section{Affiliations:}

${ }^{1}$ Department of Biochemistry, Manipal College of Medical Sciences, Pokhara, Nepal

${ }^{2}$ School of Life and Allied Health Sciences, Glocal University, Saharanpur, Uttar Pradesh, India

\section{Correspondence to:}

Dr. Imran Hussain

Assistant Professor

School of Life and Allied Health Sciences

Glocal University, Saharanpur, India

imranhussain@theglocaluniversity.in

Received: 21 Oct, $2021 \quad$ Accepted: 3 Dec, 2021

How to cite this Article:

Yadav NK, Pokheral DR, Kathayat G, Sigdel M, Hussian I. Association between serum albumin and cardiovascular disease among adult population of Kaski district, Nepal. Ann. Clin. Chem. Lab. Med. 2021:4 (1);26-30

DOI: https://doi.org/10.3126/acclm.v4i1.42678

\section{(C) 2022 Nepalese Association for Clinical Chemistry}

\section{(Q)}

This work is licensed under a Creative Commons Attribution-Share Alike 4.0 International License.

\begin{abstract}
BACKGROUND

Serum albumin is an abundant circulatory protein. Several studies were reported that a low level of serum albumin associated with a high risk of cardiovascular diseases (CVDs) mortality. Therefore, the present study aimed to investigate serum albumin levels and find out the association between serum albumin and CVDs and their correlation with cardiovascular risk factors.
\end{abstract}

\section{METHODS}

This was a cross-sectional study. Patients with confirmed CVDs were enrolled in this study while patients with CVDs plus acute or chronic liver and intestinal diseases were excluded in this study. Data were collected and analyzed by using SPSS version 21. P-value (two-tailed) $<0.05$ was considered statistically significant.

\section{RESULTS}

A total of 400 subjects were enrolled, out of which 200 healthy control (male 125 and female 75 ) and 200 patients with CVDs (male 130 and female 70). The mean level of total protein, albumin, globulin, and HDL-C were statistically $(p<0.005)$ lower while $\mathrm{TC}$, TG, and FBS were statistically $(\mathrm{p}<0.005)$ higher in CVDs subjects in compared to healthy control. The serum albumin was lower in $35(17.5 \%)$ of patients with CVDs, out of which $19(9.5 \%)$ were male and $16(8.0 \%)$ were female. Serum albumin showed a statistically significant negative correlation with age $(\mathrm{p}=0.000)$ and a positive correlation with $\mathrm{TC}(\mathrm{p}=0.000)$. In multinomial logistic regression analysis, model-I, II, and III showed a statistically significant $(\mathrm{p}<0.05)$ association between serum albumin with CVDs.

\section{CONCLUSION}

This study concluded, low serum albumin was found in patients with CVDs and it was significantly associated with CVDs. Therefore, measurement of serum albumin can be performed routinely in patients with CVDs.

KEY WORDS

Serum albumin, Cardiovascular diseases, Cardiovascular risk factors 


\section{INTRODUCTION}

Cardiovascular diseases (CVDs) are major cause of death worldwide. The cardiovascular risk factors are obesity, smoking, drinking, lipid levels, physical inactivity, diabetes mellitus, and hypertension. ${ }^{1-3}$ Several studies were reported that a low level of serum albumin associated with a high risk of CVDs mortality. ${ }^{4-6}$

Serum albumin is a negative acute-phase protein and has several vital physiological functions which include maintaining oncotic pressure and microvascular integrity, regulatating metabolic functions, antioxidant activities, providing binding ligands, and inhibiting platelet aggregation. ${ }^{7-9}$ Many studies showed that a low level of serum albumin is associated with a higher risk of myocardial infarction morbidity ${ }^{6}$, and mortality of coronary heart disease and stroke. $^{10-12}$ Inflammation is associated with CVDs incidence and mortality and serum albumin levels decrease approximately 20 percent during the inflammation process. ${ }^{13,14}$ Yang et al (2016) showed a strong association between low serum albumin levels with the occurrence of first or recurrent myocardial infarction, after adjusting for traditional risk factors. ${ }^{15}$ Based on previous studies, low serum albumin is associated with CVDs and there are no such studies were conducted in Nepali adults. Therefore, the present study aimed to investigate serum albumin levels and find out the association between serum albumin and CVDs and their correlation with cardiovascular risk factors.

\section{METHODS}

This was a cross-sectional study and was conducted in a clinical biochemistry laboratory at Manipal Teaching Hospital, Pokhara, Kaski, Nepal. The study was conducted from January 2018 to December 2020. Patients with confirmed CVDs were enrolled in this study while Patients with CVDs plus acute or chronic liver and intestinal diseases were excluded in this study.

Age, gender, family history, presence of any other diseases, dietary habits, smoking or drinking habits, and ethnicity were collected with the help of a pre-validated questionnaire. Using standard techniques and protocols, body weight, height, waist and hip circumferences, and blood pressure of all the patients were measured.
In the gel tube, five $\mathrm{ml}$ of venous blood were collected and allowed to clot then centrifuged at $4000 \mathrm{rpm}$ for 10 minutes. The serum was obtained and level of albumin, total protein, fasting blood sugar (FBS), total cholesterol (TC), triglycerides (TG), high-density lipoprotein-cholesterol (HDL-C) were measured using a fully automated dry chemistry-based analyzer (VITROS ${ }^{\circledR} 350$ chemistry system, Ortho clinical diagnostics, UK). Glycated hemoglobin (HbA1C) was measured by using a fully automated Biorad D-10 HbAlc analyzer. CVDs were defined based on one or more findings: elevated cardiac markers, abnormal ECG findings, and echocardiogram. The low albumin was defined level of $<3.5 \mathrm{gm} / \mathrm{dl}$. The written consent was obtained from all the participants before enrollment. The ethical clearance was taken from the Institutional Review Committee (IRC) of the Manipal College of Medical Sciences, Pokhara, Nepal.

The difference in means in healthy control and CVDs was found with the help of an independent student's t-test. Pearson's correlation coefficient test (two-tailed) was applied to investigate the correlation between serum albumin and CVDs risk factors. Multinomial logistic regression analysis was used to find the association between serum albumin and CVDs using SPSS version 21. P-value (two-tailed) $<0.05$ was considered statistically significant.

\section{RESULTS}

\section{Baseline characteristics of study subjects}

A total of 400 subjects were enrolled, out of which 200 healthy control (male 125 and female 75) and 200 patients with CVDs (male 130 and female 70). The mean age of healthy control and CVDs were 53.0 \pm 9.7 and $61.3 \pm 12.7$ respectively. The mean of body mass index (BMI), waist-to-hip ratio, systolic blood pressure (SBP), and diastolic blood pressure (DBP) were $24.8 \pm 2.5,0.9 \pm 0.6,118.9 \pm 7.5$, and $79.14 \pm 8.6$ in healthy control whereas $25.6 \pm 3.1,1.0 \pm 0.4,122.2 \pm 15.2$, and $78.2 \pm 10.2$ in CVDs subjects respectively. In healthy control, 18 (9\%) had smoking and 95 (47.5\%) had drinking habits.

Similarly, among CVDs subjects, 98 (49\%) had smoking and $120(60 \%)$ had drinking habits. 
Correlation of serum albumin with CVDs risk factors

Pearson's correlation analysis results were tabulated in table 1. Serum albumin showed a statistically significant correlation with age $(p=0.000)$ and TC $(p=0.000)$. The level of serum albumin showed a positive correlation with WHR, SBP, DBP, TC, TG, HDL-C, smoking habits, and drinking habits and a negative correlation with age, BMI, and FBS which showed no statistically significant $(\mathrm{p}>0.05)$.

\section{Association between serum albumin and CVDs}

Multinomial logistic regression analysis results were represented in table 2 . The different models were adjusted with CVDs risk factors. Model-I, II, and III showed a statistically significant $(p<0.05)$ association of serum albumin.

Table 1: Correlation between serum albumin and cardiovascular risk factors

\begin{tabular}{c|c|c|}
\hline \multirow{2}{*}{} & \multicolumn{2}{|c|}{ Albumin } \\
\cline { 2 - 3 } & Correlation (r) & p-value \\
\hline Age & $-0.260 * *$ & 0.000 \\
\hline BMI & -0.018 & 0.800 \\
\hline WHR & 0.010 & 0.892 \\
\hline SBP & 0.037 & 0.601 \\
\hline DBP & 0.009 & 0.905 \\
\hline FBS & -0.029 & 0.679 \\
\hline TC & $0.310 * *$ & 0.000 \\
\hline TG & 0.136 & 0.054 \\
\hline HDL-C & 0.122 & 0.084 \\
\hline Smoking habits & 0.021 & 0.768 \\
\hline Drinking habits & 0.040 & 0.574 \\
\hline
\end{tabular}

** Correlation is significant at the 0.01 level (2 -tailed). BMI (Body mass index), WHR (waistto-hip ratio), SBP (Systolic blood pressure), DBP (Diastolic blood pressure), FBS (Fasting blood sugar), TC (Total cholesterol), TG (Triglyceride), HDL-C (High-density lipoprotein-cholesterol)

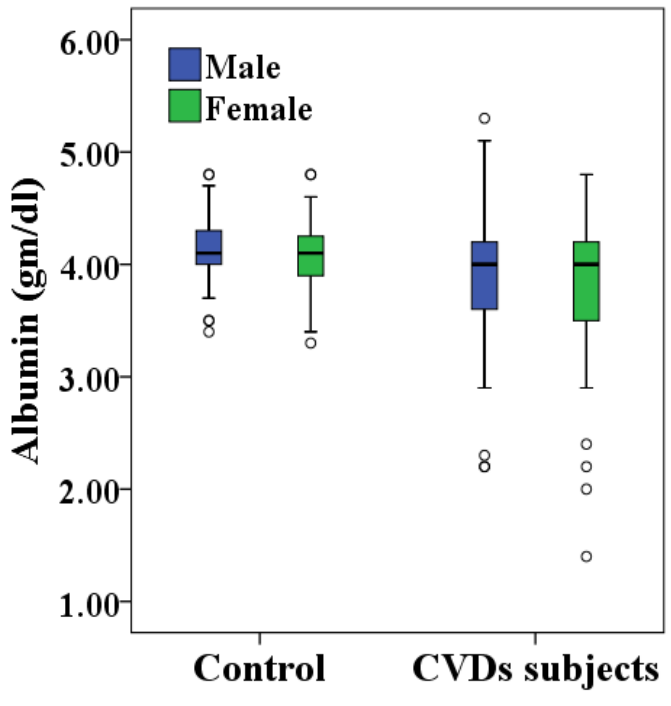

Figure 1: Serum level of albumin in control and CVDs subjects by gender. The box indicates the central data of distribution and the median is presented as a line inside the box.

Table 2: Association between serum albumin and CVDs

\begin{tabular}{c|c|c|}
\cline { 2 - 3 } & \multicolumn{2}{|c|}{ Albumin } \\
\cline { 2 - 3 } & OR $(95 \% \mathrm{CI})$ & $\mathrm{p}$-value \\
\hline Model-I & $0.372(0.215-0.644)$ & 0.000 \\
\hline Model-II & $0.405(0.201-0.816)$ & 0.011 \\
\hline Model-III & $0.348(0.149-0.813)$ & 0.015 \\
\hline Model-IV & $0.408(0.156-1.072)$ & 0.069 \\
\hline
\end{tabular}

Model-I: Adjusted for age and sex

Model-II: adjusted for age, sex, BMI, WHR, HbA1C, SBP, and DBP

Model-III: Adjusted for age, sex, BMI, WHR, HbA1C, SBP, DBP, TC, TG \& HDL-C

Model-IV: adjusted for age, sex, BMI, WHR, HbA1C, SBP, DBP, TC, TG, HDL-C, smoking habits, and drinking habits

\section{DISCUSSION}

Cardiovascular diseases are major health issues and causes of morbidity, mainly in developing countries. $^{2}$ The low level of serum albumin could act as a modifiable risk factor in patients with some cardiovascular diseases. ${ }^{16,}{ }^{17}$ In the present study, a low level of albumin was found in $17.5 \%$ of patients with CVDs. Our finding was supported by many observational studies showing the prevalence of hypoalbuminemia in different types of CVDs. 
The prevalence of hypoalbuminemia varies from one to another, $13 \%$ in stable coronary disease, $20-30 \%$ in acute coronary syndromes and myocardial infarction, $20-25 \%$ in chronic heart failure, $14-30 \%$ in congenital heart disease, stroke, and infective endocarditis. ${ }^{18-24}$ The low serum albumin results from the deceased synthesis in the liver, increased catabolism, increased vascular permeability, and loss through the kidney. ${ }^{25}$ But, these mechanisms were not investigated in the present study. However, inflammation play important role in the occurrence of hypoalbuminemia, and CVDs are directly associated with inflammation. $^{13,14}$

In the present study, serum albumin was associated with CVDs after adjustment with cardiovascular risk factors and showed a significant correlation with age and TC. Our finding was supported by several previous studies. A large population study reported that low serum albumin level was strongly associated with the occurrence of myocardial infarction, after adjusting for risk factors. ${ }^{6}$ The Framingham Offspring study reported that serum albumin was an independent predictor of first myocardial infarction. ${ }^{15}$ Some of the studies showed low serum albumin independently predicts incident heart failure. ${ }^{25-27}$

The strength of the present study was serum albumin adjusted with cardiovascular risk factors and the weakness of the study was small sample sizes and hospital-based study. Therefore, a population-based study is necessary to explore the association between serum albumin and CVDs.

\section{CONCLUSION}

This study concluded, low serum albumin was found in patients with CVDs and it was significantly associated with CVDs. Hypoalbuminemia may cause worsening of some cardiovascular conditions like heart failure, ischemic heart diseases by enhancing myocardial edema. Therefore, measurement of serum albumin can be performed routinely in patients with CVDs to decrease the worsening of the condition which may arise due to a decreased level of serum albumin.

\section{CONFLICT OF INTEREST}

None declared

\section{ACKNOWLEDGEMENT}

We want to thanks all laboratory staff, nurses of CCU, faculty of the cardiology department, and all the participants.

\section{REFERENCES}

1. Buttar HS, Li T, Ravi N. Prevention of cardiovascular diseases: Role of exercise, dietary interventions, obesity, and smoking cessation. Exp Clin Cardiol 2005; 10(4): 229-249.

2. WHO, The World Health Report 2002. Reducing Risks, Promoting Healthy Life. Geneva: World Health Organization; 2002

3. Mensah GA, Wei GS, Sorlie PD, Fine LJ, Rosenberg Y et al. Decline in Cardiovascular Mortality: Possible Causes and Implications. Circ Res 2017 20; 120(2): 366-380.

4. Phillips A, Shaper AG, Whincup PH. Association between serum albumin and mortality from cardiovascular disease, cancer, and other causes. Lancet 1989; 2(8677):1434-36.

5. Gillum RF, Makuc DM. Serum albumin, coronary heart disease, and death. Am Heart $J$ 1992; 123 (2):507-13.

6. Djousse L, Rothman KJ, Cupples LA, Levy D, Ellison RC.Serum albumin and risk of myocardial infarction and allcause mortality in the Framingham Offspring Study. Circulation 2002; 106(23):291924.

7. Caironi P, Tognoni G, Masson S, Fumagalli R, Pesenti A, et al. Albumin replacement in patients with severe sepsis or septic shock. $N$ Engl J Med 2014; 370 (15):1412-21.

8. Vincent JL, Dubois MJ, Navickis R, and. Wilkes M. Hypoalbuminemia in acute illness: is there a rationale for intervention? A meta-analysis of cohort studies and controlled trials. Annals of Surgery 2003; 237 ( 3): 319-34.

9. Chien SC, Chen CY, Lin CF, and Yeh HI. Critical appraisal of the role of serum albumin in cardiovascular disease. Biomarker Research 2017; 5( 1): 31 .

10. Weijenberg MP, Feskens EJ, Souverijn JH and Kromhout D. Serum albumin, coronary heart disease risk, and mortality in an elderly cohort. Epidemiology 1997; 8:87-92.

11. Kuller LH, Eichner JE, Orchard TJ, Grandits GA, McCallum L, et al. The relation between serum albumin levels and risk of coronary heart disease in the Multiple Risk Factor Intervention Trial. Am J Epidemiol 1991; 134:1266-77.

12. Gillum RF and Makuc DM. Serum albumin, coronary heart disease, and death. Am Heart J 1992; 123:507-13.

13. Rothschild MA, Oratz M and Schreiber SS. Serum albumin. Hepatology 1988; 8:385-401.

14. Gabay $\mathrm{C}$ and Kushner I. Acute-phase proteins and other systemic responses to inflammation. $N$ Engl $J$ Med 1999; 340:448-54. 
15. Yang Q, He YM, Cai DP, Yang XJ, Xu HF. Risk burdens of modifiable risk factors incorporating lipoprotein (a) and low serum albumin concentrations for first incident acute myocardial infarction. Sci Rep 2016; 17(6):35463.

16. Hansson GK. Inflammation, atherosclerosis, and coronary artery disease. $N$ Engl J Med 2005; 352 (16):1685-95.

17. Münzel T, Gori T, Keaney Jr, Maack C, Daiber A. Pathophysiological role of oxidative stress in systolic and diastolic heart failure and its therapeutic implications. Eur Heart J 2015; 36(38):2555-64.

18. Chien SC, Chen CY, Leu HB, Su CH, Yin WH, et al. Association of low serum albumin concentration and adverse cardiovascular events in stable coronary heart disease. Int J Cardiol 2017; 15(241):1-5.

19. González-Pacheco H, Amezcua-Guerra LM, Sandoval J, Martinez-Sanchez C, Ortiz-Leon XA, et al. Prognostic implications of serum albumin levels in patients with acute coronary syndromes. Am JCardiol 2017; 119(7):951-8.

20. Oduncu V, Erkol A, Karabay CY, Kurt M, Akgun $\mathrm{T}$, et al. The prognostic value of serum albumin levels on admission in patients with acute STsegment elevation myocardial infarction undergoing a primary percutaneous coronary intervention. Coron Artery Dis 2013; 24(2):88-94.

21. Plakht Y, Gilutz H, Shiyovich A. Decreased admission serum albumin level is an independent predictor of long-term mortality in hospital survivors of acute myocardial infarction. Soroka Acute Myocardial Infarction II (SAMI-II) project. Int J Cardiol 2016; 219:20-4.

22. Kempny A, Diller GP, Alonso-Gonzalez R,Uebing A, Rafiq I, et al. Hypoalbuminaemia predicts outcome in adult patients with congenital heart disease. Heart 2015; 101(9):699-705.

23. Zhang Q, Lei YX, Wang Q, Jin YP, Fu RL, et al. Serum albumin level is associated with the recurrence of acute ischemic stroke. Am J Emerg Med 2016 34(9):1812-6.

24. Hermiller Jr. JB, Yakubov SJ, Reardon MJ, Deeb GM, Adams DH, et al. CoreValve United States clinical investigators. Predicting early and late mortality after transcatheter aortic valve replacement. $J$ Am Coll Cardiol 2016; 68(4):34352.

25. Arques S, Ambrosi P. Human serum albumin in the clinical syndrome of heart failure. J Card Fail 2011; 17(6):451-8.

26. Gopal DM, Kalogeropoulos AP, Georgiopoulou VV, Tang WWH, Methvin A, et al. Health ABC study. Serum albumin concentration and heart failure risk the health, aging, and body composition study. Am Heart J 2010; 160(2):279-85.

27. Filippatos GS, Desai RV, Ahmed MI, Fonarrow GC, Love TE, et al. Hypoalbuminaemia and incident heart failure in older adults. Eur $J$ Heart Fail 2011; 13(10):1078-86. 